\title{
Research of variable characteristics of heat exchange equipment
}

\author{
Tatyana Rafalskaya ${ }^{1 *}$ and Valery Rudyak $^{1,2}$ \\ ${ }^{1}$ Novosibirsk State University of Architecture and Civil Engineering (Sibstrin), Leningradskaya str., 113, Novosibirsk, Russia \\ ${ }^{2}$ Novosibirsk State University, Pirogova str., 2, Novosibirsk
}

\begin{abstract}
Heat exchangers used in various industries, most often work in conditions of variable flows and temperatures. At the same time, the existing theories of calculation of heat exchanger modes are based on the use of constant dimensionless parameters in any mode of operation. The purpose of this work is to obtain dependencies to determine the effect of coolant temperatures on the variable parameter of the heat exchanger. Using the simulation method, dependencies were found that describe the change in the heat exchanger parameter which made it possible to obtain a general formula for the change in the heat exchanger parameter at varying coolant temperatures. To test the applicability of the existing relations describing the change in the heat exchanger parameter and the formula obtained, a large number of heat exchangers were calculated in variable operating modes. Comparison with the simulation results showed that the ratios of the known theories of heat exchangers do not work in all modes and their application can lead to significant errors. A formula has been obtained allows one to find the effect of coolant temperatures on the variable parameter of the heat exchanger. The formula can be used to predict the modes of large systems.
\end{abstract}

\section{Introduction}

To assess the efficiency of heat transfer processes in variable operating modes, the values used in the theory of heat exchangers are widely used, which include heat exchanger efficiency $\varepsilon, \log$ average temperature difference $\Delta t$, heat exchanger surface $F$ and the number of heat transfer units NTU. These indicators are widely used for calculating and comparing the efficiency of heat exchangers of various types $[1,2]$ in heat and power [35], aviation [6], chemical industry [7], in ventilation and air conditioning systems [8-12]. The convenience of using dimensionless complexes, such as NTU, is in the assumption that the heat transfer coefficient and the efficiency of the heat exchanger are practically independent of the temperatures of the heat exchanging media $[13,14]$. This allows to reduce the number of unknown variables which is especially important when calculating the associated heat exchanger systems, however, it is often necessary to solve the problem by the method of successive approximations [5, 12, 15]. However this assumption is valid in a fairly narrow range of temperature variation of coolants, therefore the use of constant parameters has often been criticized [2, $12,16,17]$. The effect of temperature on NTU can be estimated from the calculation formulas themselves. E.V. Stefanov [18] proposed a method for evaluating the effectiveness of irrigation spray booths using the numbers of units of transfer of apparent and total heat. For explicit heat the following equation is applied [11, 19]

$$
\mathrm{NTU}=\frac{\alpha F}{c G}=\frac{t_{11}-t_{21}}{\Delta t_{c}}
$$

where $\alpha$ is a heat transfer coefficient, $\mathrm{W} /\left(\mathrm{m}^{2} \mathrm{~K}\right) ; F$ - heat and mass transfer surface; $c$ - specific heat capacity of the coolant (humid air), $\mathrm{J} /(\mathrm{kgK}) ; \Delta t_{c}$ is an average temperature difference between air and water, ${ }^{\circ} \mathrm{C}$.

For heat recovery heat exchangers and gas cooling under dry heat exchange conditions, formula (1) takes the form $[12,20]$

$$
\mathrm{NTU}=\frac{k F}{W_{\min }},
$$

where $k$ is the heat transfer coefficient of the heat exchanger, $\mathrm{W} /\left(\mathrm{m}^{2} \mathrm{~K}\right) ; \quad W_{\min }=G c$ is the smaller equivalent of coolant flow rate, $\mathrm{W} / \mathrm{K}$.

Taking $W_{\min }=Q / \varepsilon\left(t_{11}-t_{21}\right)$ [13], where $t_{11}-t_{21}$ is the maximum temperature difference between the heating and heated coolants, and considering the dimensionless specific thermal performance (efficiency) of the heat exchanger $\varepsilon$ equal to 1 from (2), we can obtain (1)

$$
\mathrm{NTU}=\frac{k F}{W_{\min }}=\frac{Q}{\Delta t_{c} W_{\min }}=\varepsilon \frac{t_{11}-t_{21}}{\Delta t_{c}}
$$

Then at constant temperatures of coolants, at any heat output of the heat exchanger $Q$, NTU will remain

rafalskaya.ta@yandex.ru 
constant only in the case of constant volumetric flow rates of coolants, $L_{1}=L_{2}, \mathrm{~m}^{3} / \mathrm{c}$, where $L=W / \rho c$. This may be true, for example, for air-to-air heat exchangers when the flow rate of the intake air is equal to the flow rate of the exhaust air. For heat exchangers, in which the flows of the primary and secondary coolants are not equal and constantly changing, for example, for hot water heaters, the ratio (3) will not be fulfilled. Whereas the efficiency of the heat exchanger can be found as $[12$, 20]

$$
\varepsilon=\frac{W_{1}}{W_{2}} \frac{t_{11}-t_{12}}{t_{11}-t_{21}}
$$

it can be obtained that at constant temperatures of coolants in a variable mode of operation, the change in NTU will depend on the ratio of the flow of coolants.

With constant equivalents of coolant flow rates $W_{1}=W_{2}=\mathrm{const}$, the average temperature difference between the coolants, as well as larger and smaller temperature differences at the ends of the heat exchanger will be approximately equal $\Delta t_{c} \approx \delta t_{\min } \approx \delta t_{\max }$. Taking $\Delta t_{c} \approx \delta t_{\text {min }}=t_{12}-t_{21}$ from (3) and (4) we get

$$
\mathrm{NTU}=\frac{t_{11}-t_{12}}{t_{12}-t_{21}}
$$

Thus with $W_{1}=W_{2}=$ const the NTU complext will remain constant in any mode of operation if the temperatures of the heat transfer media are constant $t_{11}=$ const and $t_{21}=$ const or the temperatures of the heat transfer fluids $t_{11}$ and $t_{21}$ will change according to the same law. In other cases, temperature changes NTU will also change.

Obviously with a simultaneous change in the flow rates and temperatures of the coolants, the effect on the NTU parameter will be greater.

When calculating the variable modes of water-towater heat exchangers, the theory of heat exchangers E. Ya. Sokolov [13, 21-23] is usually used, which takes into account the large difference in the flows of primary and secondary heat carriers

$$
\mathrm{NTU}=\frac{k F}{\sqrt{W_{1} W_{2}}} .
$$

It is obvious that the simultaneous influence of both the flow rate and the temperature of the coolants on the parameter NTU in an arbitrary variable mode using (5) will be even greater. The study carried out in [17] showed that the change in the parameter NTU depends on the mode of operation of the heat exchanger, and it can be considered constant only in a certain range of ratios of temperatures and flow rates of heat transfer fluids.

This paper is devoted to the study of the influence of the temperatures of the primary and secondary coolants on the parameter of the water-to-water counter-current heat exchanger NTU in a variable mode of operation.
The goal of the paper is to obtain relations describing the change in the parameter NTU in any variable mode without intermediate calculations of the flows of heat carriers. It is assumed that the results of this study can be used to predict the operation of heat engineering equipment, build a system for regulating heat flows, and also to develop the theory of heat exchangers.

\section{Literature review}

Water-to-water heat exchangers used in heat and power systems operate at large changes in the flow rates of the heating and heated water and at temperatures of heat transfer media varying according to different temperature graphs. It is clear that in such conditions the parameter of the heat exchanger NTU cannot remain constant in any mode of operation. The nature and range of variable variables NTU depending on the mode of operation of the heat exchanger were determined in [17].

There are also widely used in practice nowadays [22, 23] methods for determining the effect of average heat carrier temperatures on a heat exchanger parameter, developed by such scientists as N. M. Singer [13] and N.N. Chistyakov et al [16].

N.M. Zinger [13] considered the influence of structural and modal factors of heat exchangers on the parameter of tubular and lamellar water heaters. Moreover in [13] it is noted that the thermophysical properties of water in the heat exchanger change little, i.e. the influence of average temperatures of heat carriers on the heat exchanger parameter is insignificant and can be described by rather simple dependencies.

Thus, for tubular heat exchangers in [13] it is noted that at constant temperatures and coolant flow rates, the specific value of NTU heater, $\mathrm{NTU}_{s}=\mathrm{NTU} / l, 1 / \mathrm{m}$, where $l$ is the total length of the tubes, is determined only by the ratio of the intertube space $f_{i t s}$ and tubes $f_{t s}$. Thus, the specific value of $\mathrm{NTU}_{s}(t)$ water-cooled sectional heaters are proposed to be determined by the approximate formula

$$
\mathrm{NTU}_{s}(t)=0.14 \varphi\left(\frac{f_{i t s}}{f_{t s}}\right)^{-0.6}\left(1+0.003 t_{i t s}^{m}\right)\left(1+0.008 t_{t s}^{m}\right),
$$

where $\varphi$ is a coefficient taking into account the effect of contamination of the heating surface of the heater is taken on average $0.75-0.85 ; t_{i t s}^{m}, t_{t s}^{m}$ are average temperatures of coolants in the intertube space and in the tubes.

For plate heat exchangers in [13], the specific parameter of the heat exchanger is determined as $\mathrm{NTU}_{\mathrm{s}}=\mathrm{NTU} / x$, where $x$ is the number of passes. The effect of average temperatures of heat exchanging media on the heat exchanger parameter NTU for heaters with plates of 0.3 and $0.6 \mathrm{~m}^{2}$, at flow rates of $0.3-0.8 \mathrm{~m} / \mathrm{s}$ and medium temperatures of coolants at the entrance to the apparatus, $25-125^{\circ} \mathrm{C}$ is determined by the formula 


$$
\mathrm{NTU}_{s}(t)=0.75+0.005 t^{m},
$$

where the average temperature of the water in the water heater is defined as the half-sum of the average temperatures of the heating and heated water.

In [20] an attempt was made to clarify the NTU parameter in variable operation modes depending on the temperatures of the heat exchanging media. Dependencies are given for a two-stage scheme of connection of hot water heaters in a heat point

- for a first stage of heater

$$
\operatorname{NTU}^{\mathrm{I}}(t)=\operatorname{NTU}\left(0.615+0.385 t_{s}\right) ;
$$

- for a second stage of heater

$$
\operatorname{NTU}^{\mathrm{II}}(t)=\mathrm{NTU}\left(0.565+0.435 t_{s}\right) .
$$

In (9) and (10) in a variable mode the average temperature of the coolants is determined depending on the outdoor temperature $t_{e x}$

- for a first stage of heater

$$
t_{s}=\left(30-t_{e x}\right) / 30 ;
$$

- for a second stage of heater

$$
t_{s}=\left(60-t_{e x}\right) / 60 .
$$

This assumption cannot be considered true, since the temperature of the heating water can change not only according to the heating and domestic schedule, but also remain constant (quantitative regulation) and the temperature of the heated water is constant at the entrance to the first stage heater at any $t_{e x}$.

Thus the existing ratios are tied to a specific type of heat exchanger (design characteristics) (7), (8), or to the scheme of their operation (9), (10), do not describe the change of parameters in any variable modes (for example, at constant temperatures of heat carriers), which requires their refinement and clarification.

\section{The new formula to determine variable heat exchanger parameters}

To determine the type and nature of the curve describing the change in the heat exchanger parameter, a countercurrent water-to-water heat exchanger was simulated in a wide range of changes in temperature and coolant flow rates, according to the method described in [17]. Modeling the effect of coolant temperatures on NTU in various variable modes made it possible to obtain a ratio, which in general terms can be written as

$$
\begin{aligned}
& \operatorname{NTU}(t)=\frac{Q}{\left(t_{p 1}-t_{h 1}\right)\left(W_{p c} W_{h c}\right)^{0,5}} \times \\
& \times\left[A+B\left(\frac{\delta t_{\text {min }}}{\delta t_{\text {max }}}\right)^{C}\right]+D
\end{aligned}
$$

where $W_{p c}$ and $W_{h c}$ are the installation equivalents of the flows of the primary and secondary coolants; $Q_{c}$ is an installation heat capacity of the heat exchanger; $\delta t_{\max }$ and $\delta t_{\min }$ are larger and smaller temperature differences at the ends of the heat exchanger.

In modes with a constant temperature of the secondary coolant or primary and secondary coolants, it is necessary to know the temperature of the coolants at the inlet to the heat exchanger and at the outlet of the heat exchanger in (13). In modes with variable coolant temperatures, it is necessary to know the temperatures of the primary and secondary coolant at the inlet to the heat exchanger and its heat output.

In (13) the expression in brackets determines the effect of coolant flow rates on the heat exchanger parameter, i.e.

$$
A+B\left(\frac{\delta t_{\min }}{\delta t_{\max }}\right)=\frac{t_{p 1}-t_{h 1}}{\Delta t}\left(\frac{W_{p c} W_{h c}}{W_{p} W_{h}}\right)^{0,5},
$$

where $W_{p}$ and $W_{h}$ are the flow rates in variable mode and the complex $B\left(\frac{\delta t_{\min }}{\delta t_{\max }}\right)^{C}$ is added when both the temperature of the coolant and the temperature of the secondary coolant at the entrance to the heat exchanger are constant.

$A, B, C, D$ the coefficients depending on the mode of operation of the heat exchanger:

$A$ determines the amount of deviation variable NTU $(t)$ from constant NTU when the heat capacity of the heat exchanger changes;

$B$ determines the magnitude of the effect of the maximum and minimum temperature difference at the ends of the heat exchanger on the $\operatorname{NTU}(t)$;

$C$ determines which of the values $\delta t_{\max }$ or $\delta t_{\min }$ has a greater impact on NTU, i.e. the direction of the curve $\mathrm{NTU}(t)$;

$D$ determines the deviation of $\mathrm{NTU}(t)$ from constant NTU in the same mode of operation depending on changes in installation conditions.

The values of the coefficients in (13) can be determined in a constructive calculation according to Table 1.

For engineering calculations, you can use the average values of the coefficients given in Table 2, while the error in the calculations in the range of the temperature difference between the coolants will be up to $10-15 \%$.

It should be noted that at a constant primary coolant temperature $t_{p 1}=$ const, the variable parameter of the heat exchanger $\mathrm{NTU}(t)$ slightly deviates from constant NTU for any changes in flow rates and the heat capacity of the heat exchanger [17] and can be determined by (5) in the installation conditions.

This is especially important when the operating temperature graph deviates from the accepted one as well as when calculating the operating modes of the tied heat exchangers where the number of unknowns is much greater than when calculating a single heat exchanger. 
Table 1. The coefficients in (13).

\begin{tabular}{|c|c|c|c|c|c|c|}
\hline \multirow{3}{*}{ Coeff. } & \multicolumn{6}{|c|}{ Heat exchanger operation mode } \\
\hline & \multirow[b]{2}{*}{$\begin{array}{l}W_{h 1}=\text { const } \\
W_{p 1}=\text { const }\end{array}$} & \multirow[b]{2}{*}{$\begin{array}{c}t_{h 1}=\text { const, } t_{p 1}=\text { const; } \\
Q=Q_{c}\end{array}$} & \multicolumn{2}{|c|}{$t_{h 1}=$ const; $Q=Q_{c}$} & \multicolumn{2}{|c|}{$t_{h 1} \neq$ const, $t_{p 1} \neq$ const, } \\
\hline & & & $t_{p 1}$ increases & $t_{p 1}$ decreases & $t_{p 1}$ increases & $\begin{array}{c}t_{p 1} \\
\text { decreases }\end{array}$ \\
\hline $\boldsymbol{A}$ & $\begin{array}{l}1.617- \\
-0.347 \frac{W_{h c}}{W_{p c}}\end{array}$ & 1 & $\begin{array}{l}0.932+ \\
+0.01\left(t_{p c 1}-t_{h c 1}\right)\end{array}$ & 1.3 & 1.7 & 0.98 \\
\hline$B$ & 0 & $\frac{\left(t_{p 1}-t_{h 1}\right) \sqrt{W_{p c} W_{h c}}}{Q_{c}}$ & $\begin{array}{l}0 \text { for }\left(t_{p c 1}-t_{h c 1}\right)>100{ }^{\circ} \mathrm{C} \\
-1 \text { for }\left(t_{p c 1}-t_{h c 1}\right) \leq 100^{\circ} \mathrm{C}\end{array}$ & $-\frac{\left(t_{p 1}-t_{h 1}\right) \sqrt{W}}{Q_{c}}$ & -1.53 & -0.87 \\
\hline C & 0 & $\begin{array}{l}{\left[1.95-0.015\left(t_{p c 1}-t_{h c 1}\right)\right] \times} \\
\times\left(1+\frac{W_{h c}}{W_{p c}}\right)\end{array}$ & 0 & $\begin{array}{l}0.248+ \\
+0.213 \frac{W_{h c}}{W_{p c}}\end{array}$ & 0 & 0 \\
\hline$D$ & 0 & $\begin{array}{l}-0.488-8.047 \times \\
\times 10^{-3}\left(t_{p c 1}-t_{h c 1}\right)+ \\
+3.131 \cdot 10^{-5} \times \\
\times\left(t_{p c 1}-t_{h c 1}\right)^{2}\end{array}$ & -0.009 & $\begin{array}{l}1.655- \\
-0.815 \frac{W_{h c}}{W_{p c}}\end{array}$ & $\begin{array}{l}0.106+ \\
+0.752 \frac{W_{h c}}{W_{p c}}\end{array}$ & $\begin{array}{l}0.086+ \\
+0.194 \frac{W_{h c}}{W_{p c}}\end{array}$ \\
\hline
\end{tabular}

Table 2. The average coefficients in (13).

\begin{tabular}{|c|c|c|c|c|c|c|}
\hline \multirow{3}{*}{ Coeff. } & \multicolumn{6}{|c|}{ Heat exchanger operation mode } \\
\hline & \multirow{2}{*}{$\begin{array}{l}W_{h 1}=\text { const } \\
W_{p 1}=\text { const }\end{array}$} & \multirow{2}{*}{$\begin{array}{c}t_{h 1}=\text { const, } t_{p 1}=\text { const; } \\
Q=Q_{c}\end{array}$} & \multicolumn{2}{|c|}{$t_{h \mathbf{1}}=$ const; $Q=Q_{c}$} & \multicolumn{2}{|c|}{$t_{h 1} \neq$ const } \\
\hline & & & $t_{p 1}$ increases & $t_{p 1}$ decreases & $\begin{array}{c}t_{p 1} \\
\text { increases }\end{array}$ & $t_{p 1}$ decreases \\
\hline$A$ & 1.46 & 1 & 2,3 & 1.3 & 1.7 & 0.98 \\
\hline $\boldsymbol{B}$ & 0 & $\frac{\left(t_{p 1}-t_{h 1}\right) \sqrt{W_{p c} W_{h c}}}{Q_{c}}$ & $\begin{array}{c}0 \text { for } \\
\left(t_{p c 1}-t_{h c 1}\right)>100{ }^{\circ} \mathrm{C} \\
-1 \text { for } \\
\left(t_{p c 1}-t_{h c 1}\right) \leq 100{ }^{\circ} \mathrm{C}\end{array}$ & $-\frac{\left(t_{p 1}-t_{h 1}\right) \sqrt{W_{p c} W_{h c}}}{Q_{c}}$ & -1.53 & -0.87 \\
\hline C & 0 & $\begin{array}{l}0.9 \text { for }\left(t_{p c 1}-t_{h c 1}\right)>50{ }^{\circ} \mathrm{C} \\
1.8 \text { for }\left(t_{p c 1}-t_{h c 1}\right) \leq 50{ }^{\circ} \mathrm{C}\end{array}$ & 0 & 0.4 & 0.4 & 0 \\
\hline$D$ & 0 & $\begin{array}{l}-0.98 \text { for }\left(t_{p c 1}-t_{h c 1}\right)>50{ }^{\circ} \mathrm{C} \\
-0.67 \text { for }\left(t_{p c 1}-t_{h c 1}\right) \leq 50{ }^{\circ} \mathrm{C}\end{array}$ & -0.009 & 0.9 & 1 & 0.2 \\
\hline
\end{tabular}

\section{Results and discussions}

To verify the adequacy and comparison of relations (6)(10) describing the variable modes of the heat exchanger, a simulation of the heat exchanger was performed, and the variable parameters $\mathrm{NTU}(t)$ in various operating modes were determined using the procedure described in [18]. The temperature range of the primary coolant was chosen in the range of 70 $150^{\circ} \mathrm{C}$, the secondary one in the range of $30-60^{\circ} \mathrm{C}$, which corresponds to the working temperature ranges of heattransfer agents in the second stage heater at the thermal point for evaluating the formulas given in [16].

In fig. 1 shows the results of calculating the modes of the heat exchanger at constant equivalents of the flows of heating and heated coolants. In the calculation, the temperature of the network water varied according to the heating schedule of $150 / 70^{\circ} \mathrm{C}$, with cutting at $70^{\circ} \mathrm{C}$. The installation heat output of the heat exchanger is $Q_{c}=$ $1200 \mathrm{~kW}$. In the case of fixed flows, the heat transfer coefficient is affected only by a change in the temperature of the heat transfer fluids. From (5) follows that $\operatorname{NTU}(t)=k F / \sqrt{W_{p c} W_{h c}}=Q /\left(\Delta t \sqrt{W_{p c} W_{h c}}\right) \sim Q / \Delta t$; those NTU $(t)$ should change along a logarithmic curve, as shown by the simulation results (curve 1); curves 2 and 3 , constructed by the (10) also describe well the dependence NTU $(t)$ (left part of the graph). In the righthand side, the temperatures of the heat carriers are constant and $\mathrm{NTU}(t) \sim Q$. At the same time (6), (7) and (9) do not reflect the actual change in $\mathrm{NTU}(t)$ especially in the region of variable temperatures of heat carriers; the use of these relations can lead to a significant error. 


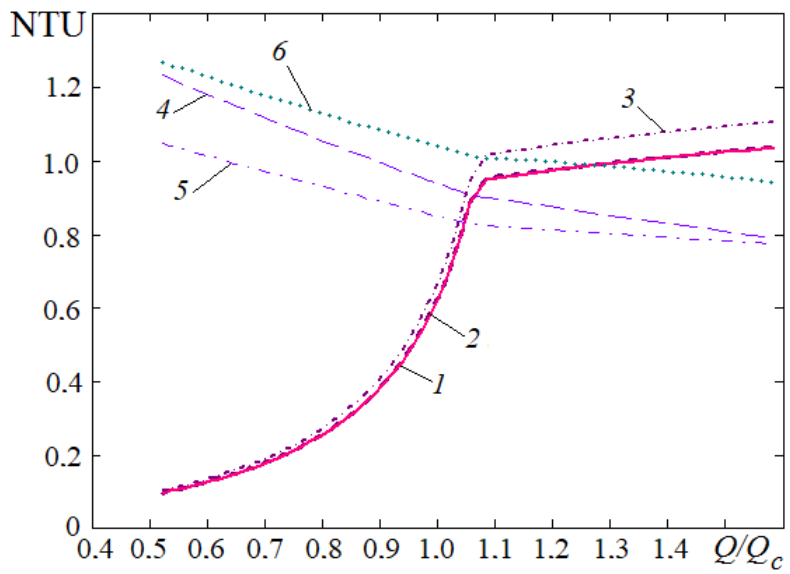

Fig. 1. Relative variable parameter of the heat exchanger with $W_{h 1}=$ const, $W_{p 1}=$ const.

In fig. 1 , number 1 is a simulation according to the method [17]; number 2 is according to (13) with the coefficients in Table I; number 3 is according to (13) with the average coefficients in Table II; number 4 is according to (7) for tubular heat exchangers [13]; number 5 is according to (8) for plate heat exchangers [13]; number 6 is according to (10) for the second stage of heater [16].

The mode at constant coolant temperatures $\left(t_{h 1}=55^{\circ} \mathrm{C}, t_{p 1}=150^{\circ} \mathrm{C}, Q_{c}=180 \mathrm{~kW}\right)$ is shown in fig. 2 . In this

$$
\operatorname{NTU}(t)=k F / \sqrt{W_{p} W_{h}}=Q /\left(\Delta t_{c} \sqrt{W_{p} W_{h}}\right) \sim Q / \sqrt{W_{p} W_{h}} ;
$$

those NTU $(t)$ will change according to the hyperbola law (line 1), which curves 2 and 3 reflect according to the (13). Relations (7), (8) and (10) are again inapplicable in this case, since they describe linear dependencies.

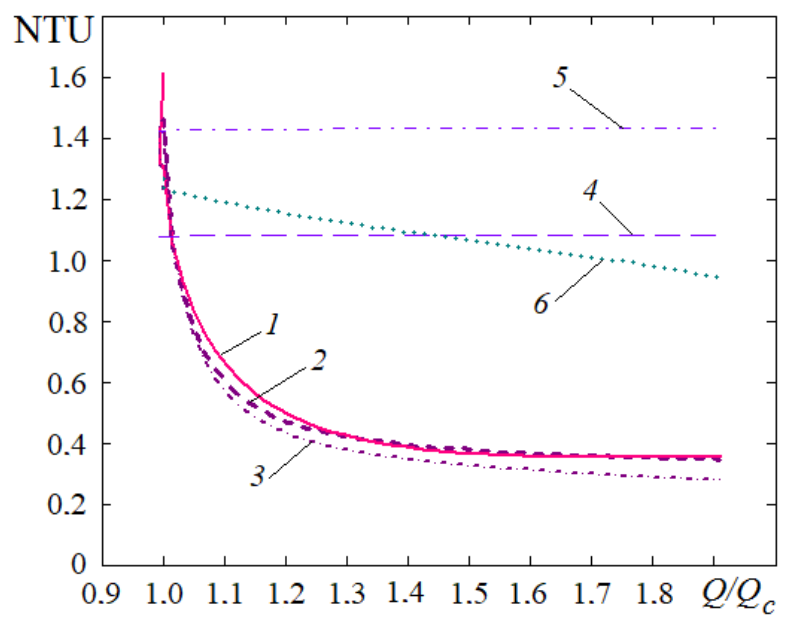

Fig. 2. Relative variable NTU of the heat exchanger with $t_{h 1}=$ const, $t_{p 1}=$ const. Numbers - see notation for fig. 1 .

For the regime with a constant temperature of the secondary coolant and the temperature of the primary coolant rises with increasing thermal power $\left(t_{h 1}=35^{\circ} \mathrm{C}\right.$, $t_{p 1}=70-130^{\circ} \mathrm{C}, Q_{c}=1300 \mathrm{~kW}$, see Fig. 3), a decrease in the primary coolant flow with increasing its temperature, therefore, the dependence of $\mathrm{NTU}(t)$ will have the form of a decreasing curve. In this case (7), (8) and (10), which do not take into account the combined effect of temperature and flow rates of heat exchanging media, also give a significant error in determining NTU $(t)$.

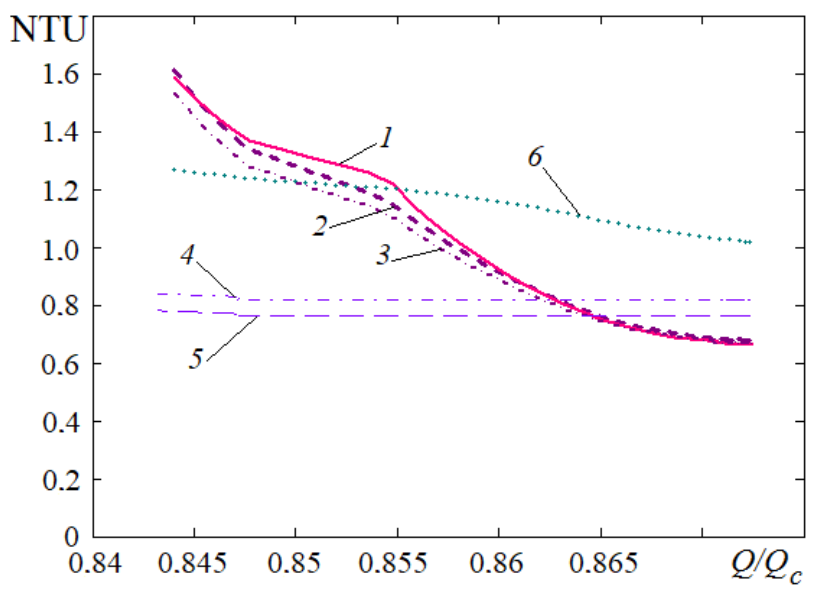

Fig. 3. The relative variable NTU of the heat exchanger with $t_{h 1}=$ const, $t_{p 1}$ increases with increasing $Q$. Numbers - see notation for fig. 1 .

At a constant temperature of the secondary coolant and a decrease in the temperature of the primary coolant with increasing thermal power $\left(t_{h 1}=35^{\circ} \mathrm{C}, t_{p 1}=150\right.$ $100^{\circ} \mathrm{C}, Q_{c}=2070 \mathrm{~kW}$, see Fig. 4), a simultaneous increase in $Q$ and the flow rate of the primary coolant compensates for the effect on the heat exchanger therefore, in this case (6) and (7) can be applied to describe the variable parameter NTU $(t)$. Relation (10) and in this case does not apply.

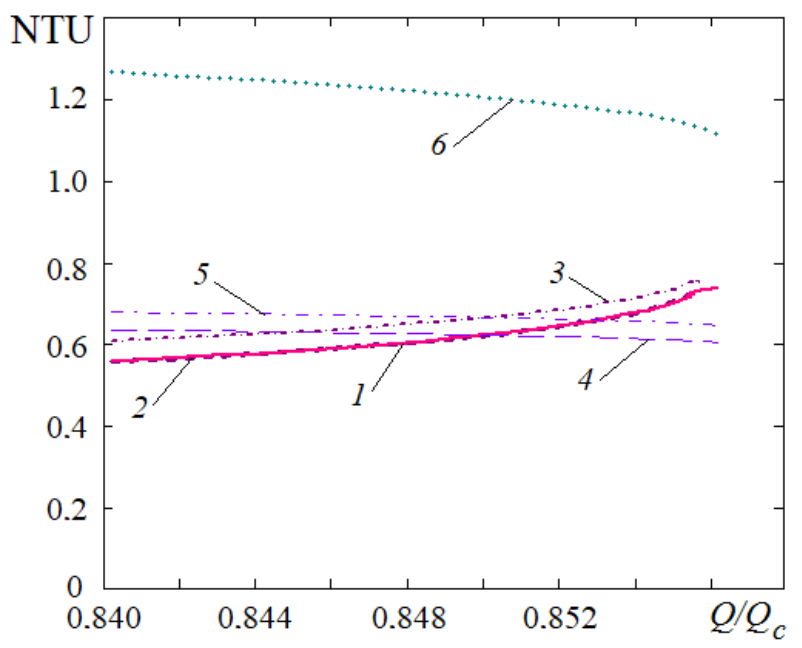

Fig. 4. Relative variable NTU of the heat exchanger with $t_{h 1}=$ const, $t_{p 1}$ decreases with increasing $Q$. Numbers - see notation for fig. 1 .

If the temperature of the secondary coolant decreases simultaneously and the temperature of the primary coolant increases with increasing thermal power $\left(t_{h 1}=65\right.$ $10^{\circ} \mathrm{C}, t_{p 1}=70-150^{\circ} \mathrm{C}, Q_{c}=270 \mathrm{~kW}$, see Fig. 5), the coolant flow rates change little and their effect on $\operatorname{NTU}(t)$ is not large, so in this case (7) and (8) can also be applied to describe the variable $\operatorname{NTU}(t)$. Relation (10) gives a big error in determining $\mathrm{NTU}(t)$ for small values of $Q$, i.e. and in this case is not applicable. 


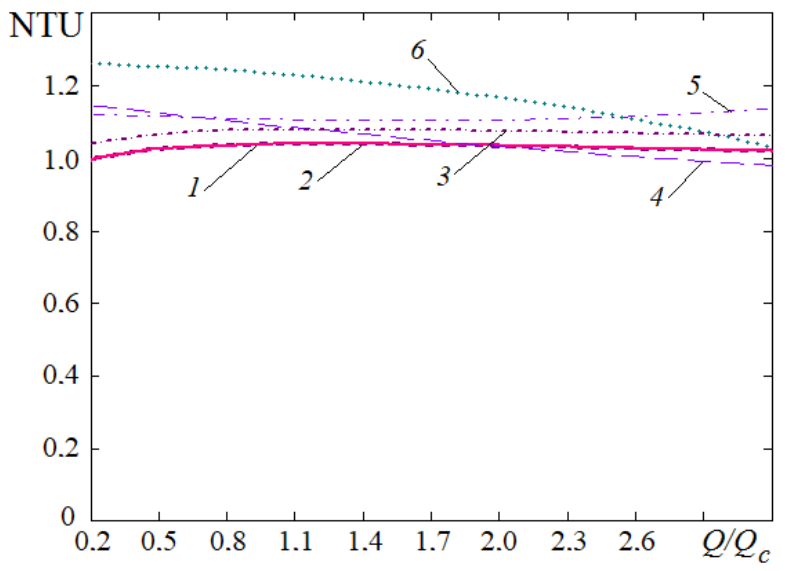

Fig. 5. Relative variable NTU of the heat exchanger with $t_{h 1}$ decreases, $t_{p 1}$ increases with increasing $Q$. Numbers - see notation for fig. 1 .

When simultaneously decreasing the temperature of the secondary coolant and primary coolant with increasing thermal power $\left(t_{h 1}=55-20^{\circ} \mathrm{C}, t_{p 1}=150-70^{\circ} \mathrm{C}\right.$, $Q_{c}=450 \mathrm{~kW}$, see Fig. 6), the primary coolant flow rate increases significantly, which affects to $\operatorname{NTU}(t)$. In this case (7), (8) and (10) cannot be applied to describe the variable $\mathrm{NTU}(t)$.

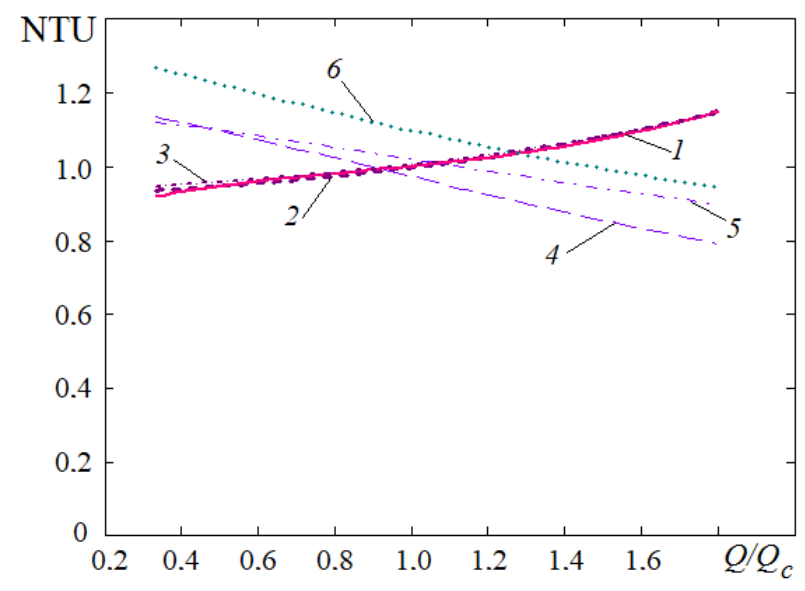

Fig. 6. Relative variable parameter of the heat exchanger with $t_{h 1}$ decreases, $t_{p 1}$ decreases with increasing $Q$. Numbers - see notation for fig. 1.

\section{Conclusions}

The ratios describing the effect of the average temperature of the coolants on the heat exchanger parameter proposed in [17] are tied to a specific type of heat exchanger and depend on its design characteristics. They can only be used for preliminary estimates in the installation mode. The formulas proposed in [16] were developed for a specific scheme for the connection of hot water heat exchangers in a heat supply station. In addition as the study showed (7)-(9) cannot be applied to describe any variable operating mode of a heat exchanger since they do not take into account the combined influence of flow rates and temperatures of heat transfer media on the heat transfer coefficient which is also noted in [13].
The proposed formula (13) makes it possible to describe any modes of operation of the heat exchanger, including the mode at constant temperatures of heat carriers, since it also takes into account the effect of changes in the flow rates of heat carriers and thermal power on the heat exchanger parameter. Relation (13) is not tied to a specific type or scheme of switching on a heat exchanger; therefore, it can be used to calculate and predict the modes of large systems consisting of several connected heat exchangers.

\section{References}

1. M. Fernández-Torrijos, C. Sobrino, D. Santana et al, $\varepsilon-N T U$ relationships in parallel series arrangements: application to plate and tubular heat exchangers, J. Appl. Therm. Eng., 99, 1119-1132 (2016).

2. G.L. Havin, Calculation of a plate heat exchanger with channels of different types in one unit, J. Problems of Mech. Eng., 14, 4, 40-45 (2011) (in Russian).

3. G.F. Nellis and S.A. Klein, Regenerative heatexchangers with significant entrained heat capacity, Int. J. of Heat and Mass Transfer, 49, 1-2, 329-340 (2006).

4. H. Mirgolbabaei, Numerical investigation of vertical helically coiled tube heat exchangers thermal performance, J. Appl. Therm. Eng., 136, 252-259 (2018).

5. E. Kaubasi and H. Kurt, Simulation of heat exchangers and heat exchanger networks with an economic aspect, J. Eng. Sc. and Techn., 70-76 (2018).

6. Yu.F. Gortyshov, E.B. Matz and I.A. Popov, Engineering method for calculating the thermal dynamic characteristics of heat exchangers, J. News of Higher Ed. Inst. Aircraft eng., 1, 29-33 (1993) (in Russian).

7. N.T. Ravi Kumar, P. Bhramara, B.M. Addis et al., Heat transfer, friction factor and effectiveness analysis of $\mathrm{Fe}_{3} \mathrm{O}_{4} /$ water nanofluid flow in a double-pipe heat exchanger with returned bend, J. Int. Com. in Heat and Mass Transfer, 81, 155-163 (2017).

8. H.A. Navarro, J.R.B.Z. Filho, G. Ribatski et al., Effectiveness - NTU data and analysis for airconditioning and refrigeration air coils, J. of the Brazilian Society of Mech. Sc. and Eng., 32, 3, 218-226 (2010).

9. C.Q. Ren, Effectiveness NTU-relation for pack bedliquid desiccant-air contact systems with a double film model for heat and mass transfer, Int. J. of Heat and Mass Transfer, 51, 7-8, 1793-1803 (2008).

10. S.B. Geni, Direct-contact condensation heat transfer on downcommerless trays for steam-water system, Int. J. of Heat and Mass Transfer, 49, 7-8, 1225-1230 (2006).

11. A.G. Averkin and A.I. Yeremkin, Improving the method of calculating devices for heat and air treatment based on the number of transfer units, J. Vestnik MGSU, 7, 362-369 (2011) (in Russian).

12. N.V. Belonogov and V.A. Pronin, Calculation of the efficiency of cross-precision plate heat exchangers, Bull. 
of the Int. Academy of Cold, 4, 12-15 (2004) (in Russian).

13. E.Ya. Sokolov, Heating and heat networks, Moscow: Publishing house MEI, 472 (2001) (in Russian).

14. N.M. Zinger, Hydraulic and thermal modes of heating systems, Moscow: Energoatomizdat, 320 (1986) (in Russian).

15. O.D. Samarin, Evaluation of the temperature efficiency of heat exchangers with an intermediate coolant by dimensionless parameters, News of Higher Ed. Inst. Const., 2, 54-58 (2009) (in Russian).

16. N.N. Chistyakov, M.M.Grudzinsky, V.I. Livchak et al, Improving the efficiency of hot water systems, Moscow: Stroiizdat, 315 (1988) (in Russian).

17. T.A. Rafalskaya and V.Ya. Rudyak, On the applicability of the ratios with constant parameters for calculation of variable modes of heat exchangers, J. News of Higher Ed. Inst. Constr., 8, 91-107 (2018) (in Russian).

18. E.V. Stefanov, Ventilation and air conditioning, St.Pt.: AVOK-North-West, 400 (2005) (in Russian).

19. A.I. Eremkin and A.G. Averkin, Improving the method of calculating contact devices for heat and moisture treatment of air, J. Constr. and Reconstr., 2(58), 105-114 (2015) (in Russian).

20. A.N. Arbekov, I.G. Surovtsev and P.B. Dermer, Heat transfer efficiency in recuperative heat exchangers with high-speed gas flows at low Prandtl numbers, J. High Temp. Therm. Ph., 52, 3, 463-468 (2014) (in Russian).

21. V.P. Gorshenin, Analysis of methods for solving the problem of central quality regulation of heat supply in water district heating systems, J. Constr. and Reconstr., 5(37), 8-13 (2011) (in Russian).

22. P.V. Rotov, Improvement of centralized heat supply systems connected to CHP plants through the development of energy efficient technologies for ensuring loads of heating and hot water supply, Thesis for the degree of Doctor of Techn. Sc., (Ulyanovsk, 410, 2015) (in Russian).

23. V.P. Chernenkov, I.D. Likhachev, M.S. Baryshev et al., Calculation of heat load control schedules in independent automated heat supply systems, Bul. of the Eng. Sch. of Far Eastern Federal University, 3(32), 2731, (2017) (in Russian). 